Electrical, Electronics and communications, and Computer Engineering

\title{
Securing Physical Layer for FHSS Communication System Using Code andPhase Hopping Techniques in CDMA, System Design and Implementation
}

\author{
Saifuldeen A.Mohammed * \\ Lecture \\ Electrical Engineering Department/University of Baghdad \\ Baghdad/Iraq \\ saifuldeen@uob.edu.iq
}

\begin{abstract}
The Frequency-hopping Spread Spectrum (FHSS) systems and techniques are using in military and civilianradar recently and in the communication system for securing the information on wireless communications link channels, for example in the Wi-Fi 8.02.X IEEE using multiple number bandwidth and frequencies in the wireless channel in order to hopping on them for increasing the security level during the broadcast, but nowadays FHSS problem, which is, any Smart Software Defined Radio (S-SDR) can easily detect a wireless signal at the transmitter and the receiver for the hopping sequence in both of these, then duplicate this sequence in order to hack the signal on both transmitter and receiver messages using the order of the sequences that will be recognized for next transmissions. In 2017 Code and Phase Hopping Techniques are both proposed to resolve the most recent problem in security-related, but not with FHSS, therefore in this paper presents a new composed proposed system will progress Phase Shift and Code Hopping in Code Division Multiplexing Access (CDMA) to complement with FHSS; because the wireless Communications systems security in the last years became a nightmare for some individuals, also companies, and even countries, also join them needing for higher bits rate in the wireless channels; because of next-generation communication system $5 \mathrm{G}-6 \mathrm{G}$ and the evolution in social networking, IoT, stream media, IoE, visualizations, and cloud computing. The new ideas can be applicable for a large number of users, also fast implementation without synchronization, as well as without any focus on encryption or keys-exchanges, at completion all results are simulation in MATLAB $\mathrm{R} 2017 \mathrm{~b}$, the results have been tested by using 8 users in the same time, also our results showing promises effects on security for both applied systems Phases Shift and Codes Hopping especially the Code Hopping, therefor; our results encouraged us to complete research and compare our system with other.
\end{abstract}

Keywords: FHSS, CDMA, Orthogonal Matrix, CHSS, PSHSS.

*Corresponding author

Peer review under the responsibility of University of Baghdad.

https://doi.org/10.31026/j.eng.2020.07.13

2520-3339 @ 2019 University of Baghdad. Production and hosting by Journal of Engineering.

This is an open access article under the CC BY4 license http://creativecommons.org/licenses/by/4.0/).

Article received: 18/3/2020

Article accepted:27/4/2020

Article published:1/7/2020 


\section{تأمين الطبقة المادية لنظام اتصالات FHSS باستخدام شفرة وتقنيات القفز الظوري في CDMA}

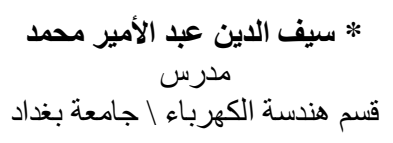

الخلاصة

تستخدم أنظمة وتقنيات طيف انتشار الترددات (FHSS) في الرادار مؤخرًا وفي نظام الاتصال لتأمين المعلومات على قنوات

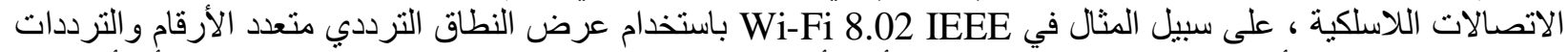

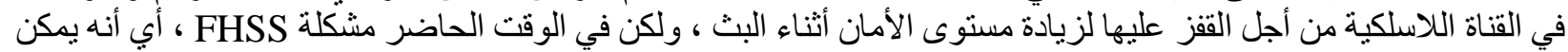

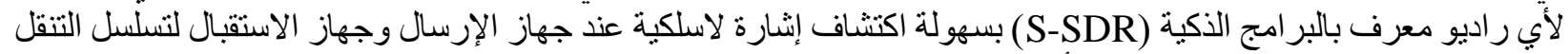

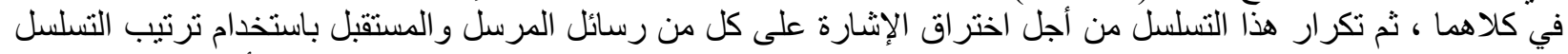

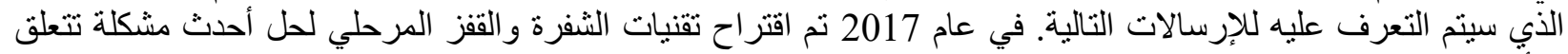

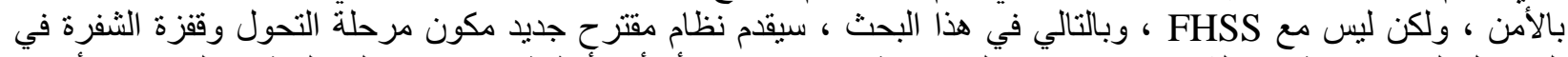

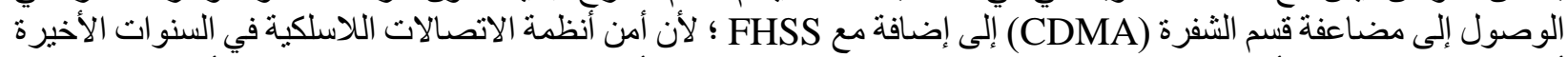

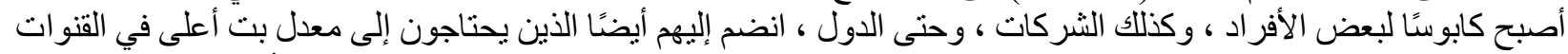

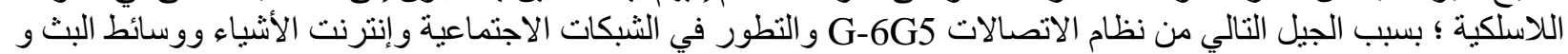

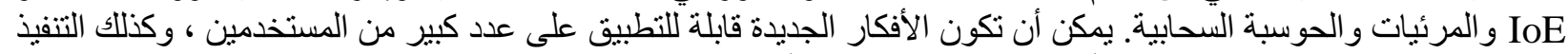

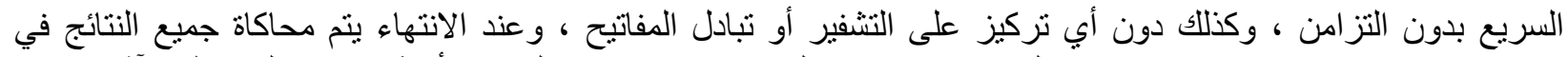

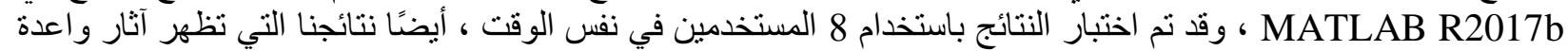
على الأمان لكل من الأنظمة المطبقة مراحل التحول و رموز التنقل وخاصةّ كود القفز ، لذلك ؛ شجعتنا نتائجنا على استكمال البحث ومقارنة نظامنا مع الآخرين.

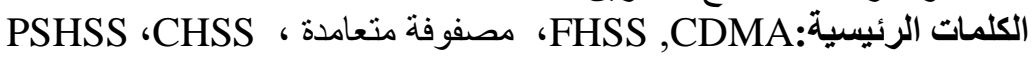

\section{INTRODUCTION for FHSS, CHSS and PSHSS}

FHSSit stands for Frequency hopping Spread Spectrum andrunningby way of the spreading bandwidth frequency of propagatingwireless wave signals, also remain to change jumping at encoded sequence order time sequence intervals. The transmitter chooses the frequencies to be used established on the spreading bandwidth frequencies sequences. Fig. 1demonstrates the block flowchart of FHSS scheme. From Fig.1 in FHSS scheme, the data is at initial step, modulated together with the carrier signal, then second phase, spreading it with spreading wave signal whose frequenciesare continuously changing. The frequency of a spreading wave signal is selected from a programmed selection frequency, and it is pinpointed just to the system clients both at the transmitter and the receiver. Consequently, the communication procedure is hard to interrupt if the used frequency of spreading signal was unknown. The equations of the broadcastwave signal of Frequency Hoppingoccursand providedby way of as Eq. (1) to (3)(Widiyatmoko et al., 2018):

$$
d_{A}(t)=u(t) \cdot c(t) \cdot \text { Fhss }(t)
$$

where $\mathrm{d}_{\mathrm{A}}(t)$ is transmitted signal of FHSS scheme, $\mathrm{u}(t)$ is user information signal, Fhss $(t)$ is the spreading wave signalfunction, and $c(t)$ is the carrier wave signalfunction. user's information signal $\mathrm{u}(t)$ is like binary data signal, while carrier signal $c(t)$ and spreading wave signal Fhss $(t)$ are not the same and they are expressed by(Widiyatmoko et al., 2018), (Visan, et al., 2019):

$$
c(t)=A * \cos \left(2 \pi f_{d} t+\theta\right)
$$




$$
\operatorname{Fhss}(\mathrm{t})=\mathrm{A} * \cos (2 \pi \mathrm{t} \cdot \mathrm{h}(\mathrm{t})+\theta)
$$

where $f_{d}$ is functionalityfor frequency of wave signal, $h(t)$ is function of hopping frequencyalso, hopping frequency $h(t)$ is a function of $h i$, in which himentions to function of spreading frequency sequence, as given by both agreement between transmitter and receiver as shown in Eq. (4):

$$
h(t)=\sum_{i=-\infty}^{\infty} h_{i} \delta\left(t-i T_{d}\right)
$$

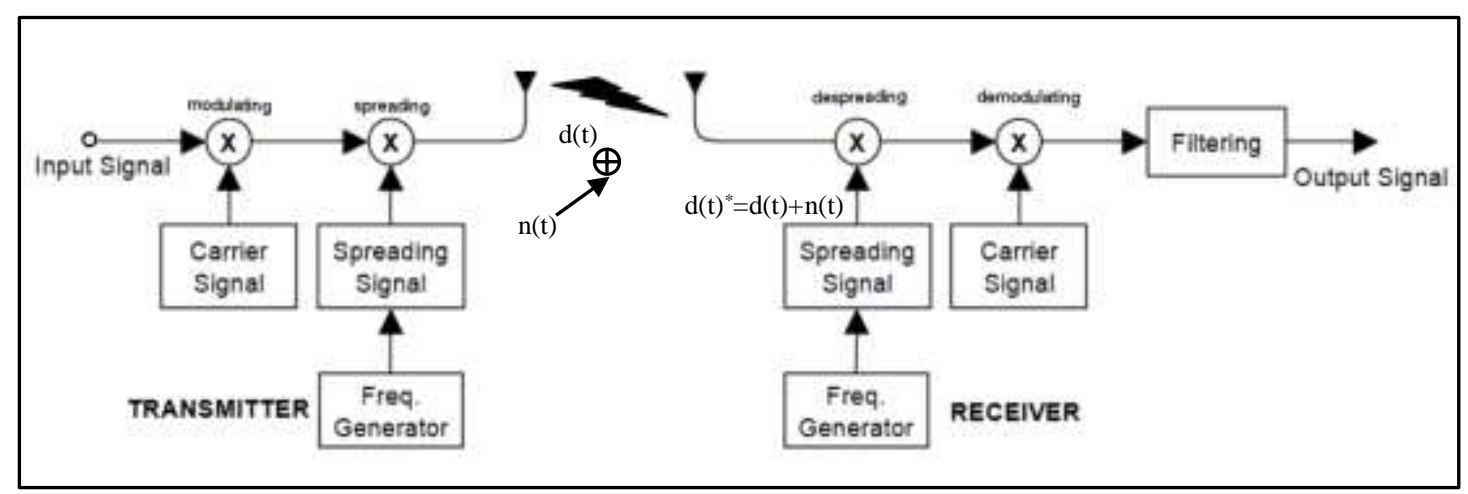

Figure 1. The FHSS System Block Diagram(Widiyatmoko et al., 2018).

Communicating system and network raise day after day and become more fast also the security(Mohammed et al., 2006), (Mohammed, 2007)therefor; FHSS is a secure techniques, day after day become more useful in different uses in both civilian and military use, like WiFi8.02X(IEEE Standard, 1997)(Vermeer, 1997)(Chayatand Breeze, 1996)and even in radar, but these days, FHSS be so vulnerable in security (Mototolea, et al., 2020)a new Smart Software Defines Radio (S-SDR), If we using it correctly ways, and If we have a smart receiver for al so (or most) for all bandwidth channels in a frequency hopping spread spectrum scheme; then we can see and recording then hear like unencrypted traffic. In SDR collection procedure, the transmitter must transmit long enough for all channels that will hopping in it, then we can collect all the frequencies to program into our receivers which is will be of course another smart SDR. there for, from above the FHSS become predictable system for its sequence order time in all next transmissions and traffic data link messaging(Mototolea, et al., 2020)(White, et al., 2019).

In the year 2017 a paper provide new novel technique on title "Phase Shift Hopping and Code Hopping in complex CDMA or JCDMA"(Mohammed, 2007)it was proposed to adding or enhancing the security progressively more by actual simple algorithm without adding any hardware stages in the old CDMA system, in further words, the Phase Shift Hopping (PSH) and Code Hopping $(\mathrm{CH})$ together work just excellentwithout slightlylargemodification in the old scheme or in bits rate and bit error rate, in other words good SNR/BER.

Moreover, in this paper, we will need this new novel system(Mohammed, 2017)(CH and PSH compacted JCDMA) to adding with FHSS, what is more for this; since today data communications systems and networks having new task in their privacy traffic and cybersecurity consequently, similarly needing a new securing systems with ultra-high bits rate, with growing in number of users and beside narrow or limited bandwidth for authorization license frequencies aimed at 
hopping in FHSS; which are further and further become major needing in ours current modern life(Mohammed, 2017), and for that it can be proposed systems that using a limitation authorization licenses frequencies or bandwidths (This is will reached in several technique like by communicated a lot users with similar frequencies and/or in same time), one of methods is TDMA (Time Division Multiplexing Access) and more successful method CDMA (Code Division Multiplexing Access) or complex CDMA (JCDMA) and MC-CDMA (Multi Carrier for Code Division Multiplexing Access) for example OFDM-CDMA (CDMAsignal companies withOrthogonal Frequency Division Multiplexing) (Mohammed, 2017),(Mohammed, 2011).

Additionally, there in 2011 and 2014 a paper deliver operating MQPSK and MQAM with in DSCDMA which is stand for(Direct Sequence CDMA)so-called JCDMA (Mohammed, 2011), (Jassim et al., 2014), the central main idea was the liberal JCDMA outputs earned complex bits rate as showed in Fig. 1, where in the finalephase, the system will work as analog system not in digital procedure, and it can be transmitter as analog wireless wavesingle with boundless bits rates like any analog transmitter system, for example Frequency Modulation sineand cosine waves or can be work with Orthogonal Frequency DivisionMultiplexing (OFDM)schemein other words as communicating analog signal to transfer digital data. Also we will try in this paper, introduce a novel new physical layer for FHSS to transmit digital data, to ensure its security when data transmission and receiver, also our new scheme probable to be smart from or through the change procedure of transmitter regularly or randomly, without any growing the number of stages or make more processing, this will guarantee the speed of the system not be reduced, this proposed system well be include mathematically proving for all equations.

To prove the orthogonality for any matrix (Seberry, 1983),(Mohammed, 2012), it is must had to multiply this matrix by its transposeconjugate and checkered whether the product is real numbers or a multiple scalar on the identity matrix or if we have matrix A was square matrix and its diminution $\mathbf{m x m}\left(\right.$ Mohammed, 2012) then $[\mathbf{M}]_{\mathbf{m x m}}$ is orthogonal matrix if:

$\mathbf{M}_{\mathrm{m}} \times \mathbf{M}_{\mathrm{m}}^{* \mathrm{~T}}=\mathrm{K} * \mathbf{I}_{\mathbf{m}}$

Anywhere"k"here is a constant number plushere any matrix "in this case square matrix", for example the most well-known orthogonal matrices besides the real and complex numbers for its elements, are Walsh Hadamard Matrix $\left(\mathbf{W H}_{\mathbf{m}}\right)$ and the Fast Fourier transform matrix $(\mathbf{F F T} \mathbf{m})$ multiplication matrix for "mxm" , Based on Eq. (1) that result from equations above, the inversereversing matrix used for $[\mathbf{W H}]_{\mathbf{m}}$ and $[\mathbf{F F T}]_{\mathbf{m}}$ is given by (Jassim et al., 2014),(Seberry, 1983),(Mohammed, 2012),(Pushnitski et al., 2008), (Beauchamp, 1984):

$\mathrm{WH}_{\mathrm{m}}^{-1}=\frac{\mathrm{WH}_{\mathrm{m}}^{\mathrm{T}}}{\mathrm{k}}$
$\mathrm{FFT}_{\mathrm{m}}^{-1}=\frac{\mathrm{FFT}_{\mathrm{m}}^{* \mathrm{~T}}}{\mathrm{k}}$ 
Where " $\mathbf{m}$ "goes on here to be the dimension of the square matrix that in this condition. Therefor the here issue will be, if the orthogonal matrix makes slight to extreme shift rotating in phase for all numbers or elements belong to the matrix as the same if the matrix will be orthogonal or not? Thus, this will proof our new tow properties in last research works (Mohammed, 2017), (Mohammed, 2012) able to applied here intended for our novel proposal scheme, then the property will be as following from paper (Mohammed, 2017):

Theorem 1: If $\mathbf{X}$ is any orthogonal not square matrices with real and complex elements, with dimension $\mathbf{m x n}$, and all elements of $\mathbf{X}: \mathbf{X} \rightarrow \mathbb{Z}$ are, then any rotating shifting all elements by the same any angle will be not square orthogonal matrix too, with scalar number, where $\mathbb{Z}$ : including the vectors numbers it are all the set for complex numbers. afterward:

Theorem 1.1 (special form): If $\mathbf{X}$ is any orthogonal square matrices with real and complex elements, with dimension $\mathbf{m x m}$, and all elements of $\mathbf{X}: \mathbf{X} \rightarrow \mathbb{Z}$ are, then any rotating shifting all elements by the same any angle will be square orthogonal matrix too, with scalar number, where $\mathbb{Z}$ : including the vectors numbers it are all the set for complex numbers.(Mohammed, 2017)

To see proof the theorem above, can see (Mohammed, 2017),(Mohammed, 2012), the key to it, it is we must persuade the orthogonal matrix's parts elements to Euler's equation formula for all elements in the matrix:

The Proof: We have that matrix $\left[\mathbf{X}_{\mathbf{m}}\right]$ orthogonal square matrix and can representing as:

$[\mathbf{X}]_{\mathrm{m} \times \mathrm{m}}=\left[\begin{array}{ccc}\mathrm{x}_{1,1} & \cdots & \mathrm{x}_{1, \mathrm{~m}} \\ \vdots & \ddots & \vdots \\ \mathrm{x}_{\mathrm{m}, 1} & \cdots & \mathrm{x}_{\mathrm{m}, \mathrm{m}}\end{array}\right]$

Where $\mathrm{x}_{1,1}=\mathrm{r}_{1,1} e^{i \theta_{1,1}} \ldots \mathrm{x}_{\mathrm{m}, \mathrm{m}}=\mathrm{r}_{\mathrm{m}, \mathrm{m}} e^{i \theta_{m, m}}$ and so on then switching all elements to Euler's equation formula:

$\begin{aligned} {[\mathbf{X}]_{\mathrm{m} \times \mathrm{m}} } & =\left[\begin{array}{ccc}\mathrm{r}_{1,1} e^{i \theta_{1,1}} & \cdots & \mathrm{r}_{1, \mathrm{~m}} e^{i \theta_{1, m}} \\ \vdots & \ddots & \vdots \\ \mathrm{r}_{\mathrm{m}, 1} e^{i \theta_{m, 1}} & \cdots & \mathrm{r}_{\mathrm{m}, \mathrm{m}} e^{i \theta_{m, m}}\end{array}\right] \\ {[\mathbf{X}]_{\mathrm{mxm}}^{* \mathrm{~T}} } & =\left[\begin{array}{ccc}\mathrm{r}_{1,1} e^{-i \theta_{1,1}} & \cdots & \mathrm{r}_{\mathrm{m}, 1} e^{-i \theta_{1, m}} \\ \vdots & \ddots & \vdots \\ \mathrm{r}_{1, \mathrm{~m}} e^{-i \theta_{m, 1}} & \cdots & \mathrm{r}_{\mathrm{m}, \mathrm{m}} e^{-i \theta_{m, m}}\end{array}\right]\end{aligned}$

Then any act on shifting for all elements to $[\mathbf{X}]_{\mathbf{m x m}}$ by the consistent angle " $\theta$ " will be:

$$
[\mathbf{X}]_{\mathrm{m} \times \mathrm{m}}^{ \pm \theta}=\left[\begin{array}{ccc}
\mathrm{r}_{1,1} e^{i\left(\theta_{1,1} \pm \theta\right)} & \cdots & \mathrm{r}_{1, \mathrm{~m}} e^{i\left(\theta_{1, n} \pm \theta\right)} \\
\vdots & \ddots & \vdots \\
\mathrm{r}_{\mathrm{m}, 1} e^{i\left(\theta_{m, 1} \pm \theta\right)} & \cdots & \mathrm{r}_{\mathrm{m}, \mathrm{m}} e^{i\left(\theta_{n, n} \pm \theta\right)}
\end{array}\right]=\left[\begin{array}{ccc}
\mathrm{r}_{1,1} e^{i \theta_{1,1}} e^{ \pm i \theta} & \cdots & \mathrm{r}_{1, \mathrm{~m}} e^{i \theta_{1, m}} e^{ \pm i \theta} \\
\vdots & \ddots & \vdots \\
\mathrm{r}_{\mathrm{m}, 1} e^{i \theta_{m, 1}} e^{ \pm i \theta} & \cdots & \mathrm{r}_{\mathrm{m}, \mathrm{m}} e^{i \theta_{m, m}} e^{ \pm i \theta}
\end{array}\right]
$$




$$
=e^{ \pm i \theta}\left[\begin{array}{ccc}
\mathrm{r}_{1,1} e^{i \theta_{1,1}} & \cdots & \mathrm{r}_{1, \mathrm{~m}} e^{i \theta_{1, m}} \\
\vdots & \ddots & \vdots \\
\mathrm{r}_{\mathrm{m}, 1} e^{i \theta_{m, 1}} & \cdots & \mathrm{r}_{\mathrm{m}, \mathrm{m}} e^{i \theta_{m, m}}
\end{array}\right]
$$

But then again, the inverse for $\mathbf{X}$ shitting by constant $\theta$ for all elements belong $[\mathbf{X}]$ will be:

$$
\begin{gathered}
e^{ \pm i \theta[\mathbf{X}]_{\mathrm{mxm}}^{* \mathrm{~T}}}=e^{ \pm i \theta}\left[\begin{array}{ccc}
\mathrm{r}_{1,1} e^{-i \theta_{1,1}} & \cdots & \mathrm{r}_{\mathrm{m}, 1} e^{-i \theta_{1, m}} \\
\vdots & \ddots & \vdots \\
\mathrm{r}_{1, \mathrm{~m}} e^{-i \theta_{m, 1}} & \cdots & \mathrm{r}_{\mathrm{m}, \mathrm{m}} e^{-i \theta_{m, m}}
\end{array}\right] \\
{\left[\begin{array}{ccc}
\mathrm{r}_{1,1} e^{i\left(-\theta_{1,1} \pm \theta\right)} & \cdots & \mathrm{r}_{\mathrm{m}, 1} e^{i\left(-\theta_{1, m} \pm \theta\right)} \\
\vdots & \ddots & \vdots \\
\mathrm{r}_{1, \mathrm{~m}} e^{i\left(-\theta_{m, 1} \pm \theta\right)} & \cdots & \mathrm{r}_{\mathrm{m}, \mathrm{m}} e^{i\left(-\theta_{m, m} \pm \theta\right)}
\end{array}\right]}
\end{gathered}
$$

And $e^{ \pm i \theta}[\mathbf{X}]_{\mathrm{m} \times \mathrm{m}} \times e^{ \pm i \theta}[\mathbf{X}]_{\mathrm{mxm}}^{* \mathrm{~T}}=e^{ \pm 2 i \theta}[\mathbf{I}]_{\mathrm{m} \times \mathrm{m}} \quad$ or $\quad=\mathrm{k} e^{ \pm 2 i \theta}[\mathbf{I}]_{\mathrm{m} \times \mathrm{m}}$ and $[\mathbf{X}]_{\mathrm{m} \times \mathrm{m}}^{ \pm \theta^{-1}}=$ $e^{ \pm i(-\theta)}[\mathbf{A X}]_{\mathrm{mxm}}^{* \mathrm{~T}} / \mathrm{k}$, Where: $\mathrm{x}_{\mathrm{mxm}}$ is $\mathbf{X}$ elements, $\mathrm{r}_{\mathrm{m}, \mathrm{m}}$ is the distance from origin or the radius of the unity circle, $\mathrm{K}$ is a constant and $[\mathbf{I}]_{\mathbf{m} \times \mathbf{m}}$ is identical matrix.

At hand, for the last equations evidencewhich is "if any shifting in phases for all elements to any orthogonal matrix is even so or will be orthogonal matrix too, but with adding together a constant as multiply number equal $\left(\mathbf{e}^{ \pm \mathbf{i} \boldsymbol{\theta}}\right)$ )" then the next section will contest the proposed system for using FHSS Phase Hopping with CDMA and complex CDMA the "JCDMA" for sample (but it can be used in OFDM and any digital communication similar to M-QAM), it will be adding together this feature assynthesis for fine-tuning radio station!!.

Followingour derivatizing equations over, now and immediatelywe will must be discoveryinformal and innovative procedure for produce orthogonal matrices in different dimensions for using in Code Hopping Spared Spectrums with FHSS (CHSS) since the oldenmethodsare very complex and problematic to calculate in real time processing even in current computers, swell that and since orthogonal matrices can be used in several different applications, for example similar to image processing and wireless $3 \mathrm{G}$ communications (in CDMA or OFDM or together).

Therefor; in this paper, we represent how ournovel method generate and findingvarious orthogonal matrices throughapplying tensor products amongseveral orthogonal matrices, tow or more, in bothformation, real and complex numbers for matrix'selements, with affecting it in telecommunication(Jassim et al., 2013), (Mohammed, 2012), then Code Hopping with FHSS Spread Spectrum will be (CHSS) the person who reads will realize on the finishing line of this section that yielded matrices will remain orthogonal matrices too and the processing thru the novel method is actual easy way.

The tensor product in this paperwill be Kronecker product, can be useful in different actions like in matrices, vectors, Algebras, topological vector, modules,andspacing calculations.....etc., among many other forms or things(Jassim et al., 2013). The most common bilinear trick, in some frameworks, was the tensor product and is additionally referred to as outer matrices product. For linear algebra mapping action for together[A], [B] (represented by matrices here), then, the type of matrix tensor product for two or more matricesand there are many properties for tensor product, but in this paper, will represent 
ournovel and actualsuitable way also its important for create orthogonal code can use for (CHSS) implementation were Theorem 2 and 2.1 descript this way to find many orthogonal matrices using as codes but the full proof for this new theorem can find in both reference (Jassim et al., 2013),(Mohammed, 2012) with all details and opportunity in applications.

Theorem 2 If $\mathbf{X}: \mathbb{Z} \rightarrow \mathbb{Z}$ and $\mathbf{Y}: \mathbb{Z} \rightarrow \mathbb{Z}$ are not square orthogonal matrices, so any actthrough their tensor product by matrix form is given by $(\mathbf{X} \otimes \mathbf{Y}=\mathbf{C}: \mathbb{Z} \rightarrow \mathbb{Z})$ the resulting matrix $\mathbf{C}$ will be not square orthogonal too, which is the set for complex numbers including the vectors numbers.

Theorem 2.1 (Special form) If $\mathbf{X}: \mathbb{Z} \rightarrow \mathbb{Z}$ and $\mathbf{Y}: \mathbb{Z} \rightarrow \mathbb{Z}$ are square orthogonal matrices, then any action by their tensor product by matrix form is given by $(\mathbf{X} \otimes \mathbf{Y}=\mathbf{C}: \mathbb{Z} \rightarrow \mathbb{Z})$ the resulting matrix $\mathbf{C}$ will be square orthogonal too, which is the set for complex numbers including the vectors numbers.

The proof for Theorem 2.1, for square matrices, you can see all complete details in the (Jassim e $\mathbf{t}$ al., 2013)but we have that the full proof here is more useful:

If we have $[\mathbf{A}]_{\mathrm{n} \times \mathrm{n}}=\left[\begin{array}{ccc}\mathrm{a}_{1,1} & \cdots & \mathrm{a}_{1, \mathrm{n}} \\ \vdots & \ddots & \vdots \\ \mathrm{a}_{\mathrm{n}, 1} & \cdots & \mathrm{a}_{\mathrm{n}, \mathrm{n}}\end{array}\right]$ and $[\mathbf{B}]_{\mathrm{m} \times \mathrm{m}}=\left[\begin{array}{ccc}\mathrm{b}_{1,1} & \cdots & \mathrm{b}_{1, \mathrm{~m}} \\ \vdots & \ddots & \vdots \\ \mathrm{b}_{\mathrm{m}, 1} & \cdots & \mathrm{b}_{\mathrm{m}, \mathrm{m}}\end{array}\right]$

both orthogonal square matrices then:

$$
\begin{aligned}
& {[\mathbf{C}]_{(\mathrm{n} * \mathrm{~m}) \times(\mathrm{n} * \mathrm{~m})}=[\mathbf{A}]_{\mathrm{n} \times \mathrm{n}} \otimes[\mathbf{B}]_{\mathrm{m} \times \mathrm{m}}=\left[\begin{array}{ccc}
\mathrm{a}_{1,1} *[\mathbf{B}] & \cdots & \mathrm{a}_{1, \mathrm{n}} *[\mathbf{B}] \\
\vdots & \ddots & \vdots \\
\mathrm{a}_{\mathrm{n}, 1} *[\mathbf{B}] & \cdots & \mathrm{a}_{\mathrm{n}, \mathrm{n}} *[\mathbf{B}]
\end{array}\right]=}
\end{aligned}
$$

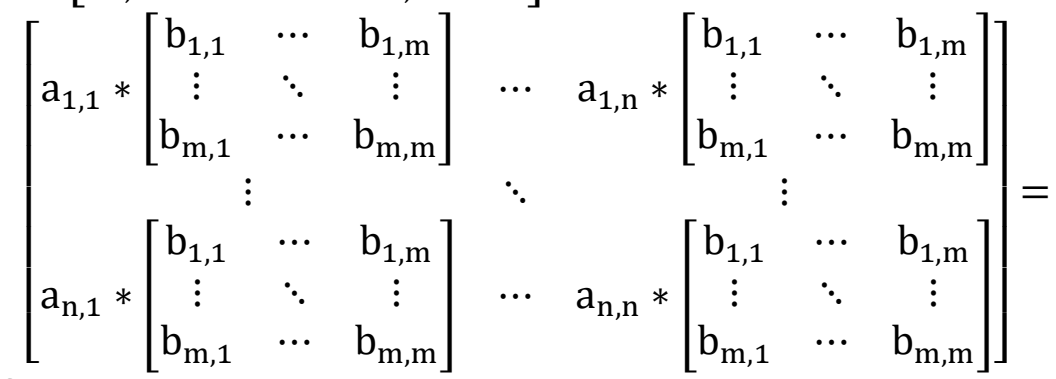

$$
\begin{aligned}
& {\left[\begin{array}{ccc}
\mathrm{c}_{1,1} & \cdots & \mathrm{c}_{1,(\mathrm{n} * \mathrm{~m})} \\
\vdots & \ddots & \vdots \\
\mathrm{c}_{(\mathrm{n} * \mathrm{~m}), 1} & \cdots & \mathrm{c}_{(\mathrm{n} * \mathrm{~m}),(\mathrm{n} * \mathrm{~m})}
\end{array}\right] \text { wherec }_{1,1}=\mathrm{a}_{1,1} * \mathrm{~b}_{1,1} \cdots \cdots}
\end{aligned}
$$

While we right now having $\mathbf{A}^{* \mathrm{~T}} \otimes \mathbf{B}^{* \mathrm{~T}}=(\mathbf{A} \otimes \mathbf{B})^{* \mathrm{~T}}=\mathbf{C}^{* \mathrm{~T}}$, so we need proof that $\mathbf{C}^{*} \mathbf{C}^{* \mathrm{~T}}=k \mathbf{I}=k$ $[\mathbf{I}]_{(\mathrm{n} * \mathrm{~m}) \times(\mathrm{n} * \mathrm{~m})}=[\mathbf{C}]_{(\mathrm{n} * \mathrm{~m}) \times(\mathrm{n} * \mathrm{~m})} *[\mathbf{C}]_{(\mathrm{n} * \mathrm{~m}) \times(\mathrm{n} * \mathrm{~m})} * \mathrm{~T}=$

$$
\begin{gathered}
\left([\mathbf{A}]_{\mathrm{n} \times \mathrm{n}} \otimes[\mathbf{B}]_{\mathrm{m} \times \mathrm{m}}\right) *\left([\mathbf{A}]_{\mathrm{n} \times \mathrm{n}} * \mathrm{~T} \otimes[\mathbf{B}]_{\mathrm{m} \times \mathrm{m}}{ }^{* \mathrm{~T}}\right)= \\
=\left[\begin{array}{ccc}
\mathrm{a}_{1,1} *[\mathbf{B}] & \cdots & \mathrm{a}_{1, \mathrm{n}} *[\mathbf{B}] \\
\vdots & \ddots & \vdots \\
\mathrm{a}_{\mathrm{n}, 1} *[\mathbf{B}] & \cdots & \mathrm{a}_{\mathrm{n}, \mathrm{n}} *[\mathbf{B}]
\end{array}\right] *\left[\begin{array}{ccc}
\mathrm{a}_{1,1}{ }^{*} *[\mathbf{B}]^{* \mathrm{~T}} & \cdots & \mathrm{a}_{\mathrm{n}, 1}{ }^{*} *[\mathbf{B}]^{* \mathrm{~T}} \\
\vdots & \ddots & \vdots \\
\mathrm{a}_{1, \mathrm{n}}{ }^{*} *[\mathbf{B}]^{* \mathrm{~T}} & \cdots & \mathrm{a}_{\mathrm{n}, \mathrm{n}} *[\mathbf{B}]^{* \mathrm{~T}}
\end{array}\right]
\end{gathered}
$$




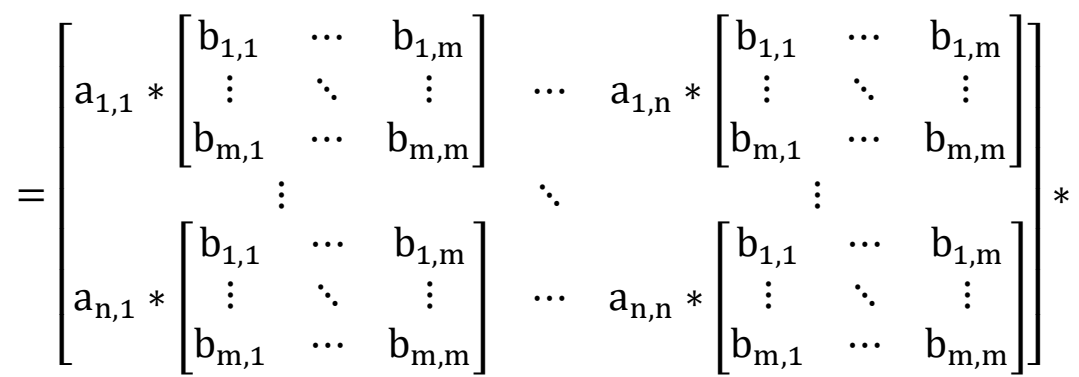

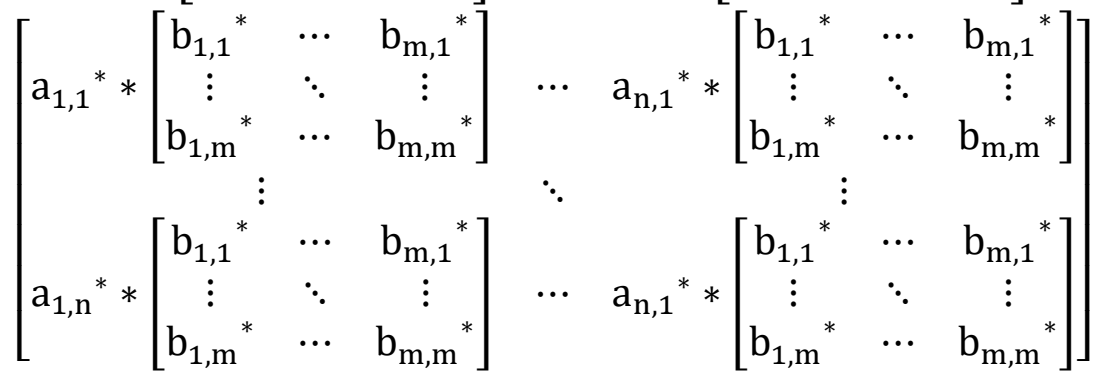

Buthere, we take the first row to the $[\mathbf{C}]$ then once again,then we willget new equation:

$$
\begin{array}{r}
\mathrm{k} * 1=\mathrm{a}_{1,1} \mathrm{a}_{1,1}^{*}\left(\mathrm{~b}_{1,1} \mathrm{~b}_{1,1}^{*}+\mathrm{b}_{1,2} \mathrm{~b}_{1,2}^{*} \ldots \ldots \ldots \mathrm{b}_{1, \mathrm{~m}} \mathrm{~b}_{1, \mathrm{~m}}^{*}\right) \\
+\mathrm{a}_{1,2} \mathrm{a}_{1,2}^{*}\left(\mathrm{~b}_{1,1} \mathrm{~b}_{1,1}^{*}+\mathrm{b}_{1,2} \mathrm{~b}_{1,2}^{*} \ldots \ldots \ldots \mathrm{b}_{1, \mathrm{~m}} \mathrm{~b}_{1, \mathrm{~m}}^{*}\right)+\ldots . \\
\ldots+\mathrm{a}_{1, \mathrm{n}} \mathrm{a}_{1, \mathrm{n}}^{*}\left(\mathrm{~b}_{1,1} \mathrm{~b}_{1,1}^{*}+\mathrm{b}_{1,2} \mathrm{~b}_{1,2}^{*} \ldots \ldots \ldots \mathrm{b}_{1, \mathrm{~m}} \mathrm{~b}_{1, \mathrm{~m}}^{*}\right) \\
\mathrm{k} * 1=\sum_{i=1}^{n}\left(\begin{array}{r}
\left.\left(\mathrm{a}_{1, \mathrm{i}} * \mathrm{a}_{1, \mathrm{i}}^{*}\right) * \sum_{j=1}^{m}\left(\mathrm{~b}_{1, \mathrm{j}} * \mathrm{~b}_{1, \mathrm{j}}^{*}\right)\right)
\end{array}\right.
\end{array}
$$

For thereason directly above, $[\mathbf{B}]$ will be orthogonal after that:

$\left(\mathrm{b}_{1,1} \mathrm{~b}_{1,1}^{*}+\mathrm{b}_{1,2} \mathrm{~b}_{1,2}^{*} \ldots \ldots \ldots \mathrm{b}_{1, \mathrm{~m}} \mathrm{~b}_{1, \mathrm{~m}}^{*}\right)=\sum_{j=1}^{m}\left(\mathrm{~b}_{1, \mathrm{j}} * \mathrm{~b}_{1, \mathrm{j}}^{*}\right)=1$ ork $k_{2}($ If Not $=0)$ then the equations will be:

$\sum_{i=1}^{n}\left(\left(\mathrm{a}_{1, \mathrm{i}} * \mathrm{a}_{1, \mathrm{i}}^{*}\right) * \sum_{j=1}^{m}\left(\mathrm{~b}_{1, \mathrm{j}} * \mathrm{~b}_{1, \mathrm{j}}^{*}\right)\right)=\left(1\right.$ or $\left.k_{2}\right) \sum_{i=1}^{n}\left(\mathrm{a}_{1, \mathrm{i}} * \mathrm{a}_{1, \mathrm{i}}^{*}\right)$

and for the reason over, [A] will be orthogonal too,so the equation will be present at this point: $\sum_{i=1}^{n}\left(\mathrm{a}_{1, \mathrm{i}} * \mathrm{a}_{1, \mathrm{i}}^{*}\right)=\left(1\right.$ or $\left.k_{1}\right)$ (If Not $\left.=0\right)$; thus:

$$
\sum_{i=1}^{n}\left(\left(\mathrm{a}_{1, \mathrm{i}} * \mathrm{a}_{1, \mathrm{i}}^{*}\right) * \sum_{j=1}^{m}\left(\mathrm{~b}_{1, \mathrm{j}} * \mathrm{~b}_{1, \mathrm{j}}^{*}\right)\right)=\left(1 \text { or } k_{2}\right) *\left(1 \text { or } k_{1}\right)=k
$$

For the second row for $[\mathbf{C}]$ will be present at this point as:

$$
\begin{aligned}
& 0=a_{2,1} a_{1,1}^{*}\left(b_{1,1} b_{1,1}^{*}\right.\left.+b_{1,2} b_{1,2}^{*} \ldots \ldots \ldots b_{1, m} b_{1, m}^{*}\right) \\
&+a_{2,2} a_{1,2}^{*}\left(b_{1,1} b_{1,1}^{*}+b_{1,2} b_{1,2}^{*} \ldots \ldots \ldots b_{1, m} b_{1, m}^{*}\right)+\ldots \ldots \\
& \ldots+a_{2, n} a_{1, n}^{*}\left(b_{1,1} b_{1,1}^{*}+b_{1,2} b_{1,2}^{*} \ldots \ldots \ldots b_{1, m} b_{1, m}^{*}\right)
\end{aligned}
$$


$0=\sum_{i=1}^{n}\left(\left(\mathrm{a}_{2, \mathrm{i}} * \mathrm{a}_{1, \mathrm{i}}^{*}\right) * \sum_{j=1}^{m}\left(\mathrm{~b}_{1, \mathrm{j}} * \mathrm{~b}_{1, \mathrm{j}}^{*}\right)\right)$

Since $\sum_{j=1}^{m}\left(\mathrm{~b}_{1, \mathrm{j}} * \mathrm{~b}_{1, \mathrm{j}}^{*}\right)=\left(1\right.$ or $\left._{2}\right)$ but: $\sum_{i=1}^{n}\left(\mathrm{a}_{\mathrm{t}, \mathrm{i}} * \mathrm{a}_{1, \mathrm{i}}^{*}\right)=\left\{\begin{array}{l}0 \text { if } \mathrm{t} \neq \mathrm{l} \\ 1 \text { if } \mathrm{t}=\mathrm{l}\end{array}\right.$; thus:

This is extremelyfavored property for orthogonally utilized to the matrices; consequently[C] $\mathrm{W}$ ill be orthogonal square, as shown below:

$k[\mathbf{I}]_{(\mathrm{n} * \mathrm{~m}) \times(\mathrm{n} * \mathrm{~m})}=\left[\begin{array}{ccc}\mathrm{c}_{1,1} & \cdots & \mathrm{c}_{1,(\mathrm{n} * \mathrm{~m})} \\ \vdots & \ddots & \vdots \\ \mathrm{c}_{(\mathrm{n} * \mathrm{~m}), 1} & \cdots & \mathrm{c}_{(\mathrm{n} * \mathrm{~m}),(\mathrm{n} * \mathrm{~m})}\end{array}\right] *\left[\begin{array}{ccc}\mathrm{c}_{1,1}{ }^{*} & \cdots & \mathrm{c}_{1,(\mathrm{n} * \mathrm{~m})}{ }^{*} \\ \vdots & \ddots & \vdots \\ \mathrm{c}_{(\mathrm{n} * \mathrm{~m}), 1} & \cdots & \mathrm{c}_{(\mathrm{n} * \mathrm{~m}),(\mathrm{n} * \mathrm{~m})}\end{array}\right]$

wherec $_{1,1}=\mathrm{a}_{1,1} * \mathrm{~b}_{1,1} \cdots$

This ending the proof

\section{EQUATIONSANDFORMATTING PHASE SHIFT HOPPING, CODE HOPPING ANDJCDMA IN FHSS}

Primary, JCDMA ( Complex numbers mapping Code Division Multiple Access) its spiritual and standpointidentical tomaking a special exclusive label for every user's customerinfo data in the network subscript; to guarantee at demodulation and success the info data will be not stiff to the users, puttingusers informationwhile the equations under,where in Fig. 2the serial to parallel is $1: \mathrm{N}_{\mathrm{k}-1}$, (Mohammed, 2011), nextour equations in (Mohammed, 2011) will be if $\mathrm{PN}_{\mathrm{n}}$ and $\mathrm{JPN}_{\mathrm{n}}$ for all users is equally to one, will be as below:

$$
\begin{aligned}
& {[\text { CODE }]=\left[\begin{array}{c}
\text { Code }_{1} \\
\text { Code }_{2} \\
\vdots \\
\text { Code }_{n}
\end{array}\right] \text {, and: }[\text { CODE }] \cdot[\text { CODE }]^{* T}=[\mathrm{I}]_{\mathrm{n} \times \mathrm{n}}} \\
& \text { Code }_{\mathrm{n}}=\left\{\mathrm{C}_{(\mathrm{n}, \mathrm{m})}\right\}_{\mathrm{m}=1}^{\mathrm{L}} \\
& \mathrm{d}_{\mathrm{cn}}=\mathrm{U}_{\mathrm{n}} \mathrm{PN}_{\mathrm{n}} \operatorname{Code}_{\mathrm{n}}=\mathrm{U}_{\mathrm{n}} \mathrm{PN}_{\mathrm{n}}\left\{\mathrm{C}_{(\mathrm{n}, \mathrm{m})}\right\}_{\mathrm{m}=1}^{\mathrm{L}}=\mathrm{U}_{\mathrm{n}}\left\{\mathrm{C}_{(\mathrm{n}, \mathrm{m})}\right\}_{\mathrm{m}=1}^{\mathrm{L}=1} \\
& \mathrm{~d}_{\mathrm{A}}=\sum_{\mathrm{k}=0}^{\mathrm{n}-1} \mathrm{U}_{\mathrm{k}} \mathrm{PN}_{\mathrm{k}} \operatorname{Code}_{\mathrm{k}}=\sum_{\mathrm{k}=0}^{\mathrm{n}-1} \mathrm{U}_{\mathrm{K}}^{\mathrm{G}} \mathrm{PN}_{\mathrm{K}}^{\mathrm{G}}\left\{\mathrm{C}_{(\mathrm{k}+1, \mathrm{~m})}\right\}_{\mathrm{m}=1}^{\mathrm{L}}=\sum_{\mathrm{k}=0}^{\mathrm{n}-1} \mathrm{U}_{\mathrm{K}}^{\mathrm{G}}\left\{\mathrm{C}_{(\mathrm{k}+1, \mathrm{~m})}\right\}_{\mathrm{m}=1}^{\mathrm{L}}
\end{aligned}
$$

And sinceEq. 22, 23and 24 it is can here transmitter many chips packages and the total sum can be representative ofsuch as a series notation as Eq. 24, if the user number of data chips for messages are here is $(G)$ or sequence for time (Mohammed, 2011), (Jassim et al., 2014)soEq. 24 will be revisionsuch as:

$\mathrm{d}_{\mathrm{A}}^{\mathrm{G}}=\left\{\sum_{\mathrm{k}=0}^{\mathrm{n}-1} \mathrm{U}_{\mathrm{K}}^{\mathrm{G}} \mathrm{PN}_{\mathrm{K}}^{\mathrm{G}} \operatorname{Code}_{\mathrm{k}}\right\}_{1}^{\mathrm{G}}=\left\{\sum_{\mathrm{k}=0}^{\mathrm{n}-1} \mathrm{U}_{\mathrm{K}}^{\mathrm{G}} \mathrm{PN}_{\mathrm{K}}^{\mathrm{G}}\left\{\mathrm{C}_{(\mathrm{k}+1, \mathrm{~m})}\right\}_{\mathrm{m}=1}^{\mathrm{L}}\right\}_{1}^{\mathrm{G}}=\left\{\sum_{\mathrm{k}=0}^{\mathrm{n}-1} \mathrm{U}_{\mathrm{K}}^{\mathrm{G}}\left\{\mathrm{C}_{(\mathrm{k}+1, \mathrm{~m})}\right\}_{\mathrm{m}=1}^{\mathrm{L}}\right\}_{1}^{\mathrm{G}}$

As from above in Eq. 25 it is can reachedlowest bandwidth for one chip in Eq. 23 and 24, the parameter requirement tostand in the impropersmallest length or $\mathrm{d}_{\mathrm{A}}$ must be smallestmodel and that can stand if and only if Code $\mathbf{k}_{\mathbf{k}}$ remain in the minimum; yet it is so rigid and difficult to create and originatesmallest code, in this situation must remain orthogonal and only if the length of it will be at least is equal to number of users, therefor the condition equation designed 
for JCDMA will standequallyEq. 25 and26(Mohammed, 2011), (Jassim et al., 2014)the equal as below with $\left(\mathrm{JPN}_{\mathrm{n}}=1\right)$ :

$\mathrm{d}_{\mathrm{A}}^{\mathrm{G}}=\left\{\sum_{\mathrm{k}=0}^{\mathrm{n}-1} \mathrm{Uq}_{\mathrm{K}}^{\mathrm{G}} \mathrm{JPN}_{\mathrm{K}}^{\mathrm{G}} \operatorname{Code}_{\mathrm{k}}\right\}_{1}^{\mathrm{G}}=\left\{\sum_{\mathrm{k}=0}^{\mathrm{n}-1} \mathrm{Uq}_{\mathrm{K}}^{\mathrm{G}}\left\{\mathrm{C}_{(\mathrm{k}+1, \mathrm{~m})}\right\}_{\mathrm{m}=1}^{\mathrm{L}}\right\}_{1}^{\mathrm{G}}$

Where at this point in Eq. $26, \mathbf{U q}_{K}^{\mathrm{G}}=\mathbf{2}^{\mathbf{n}} \mathbf{Q A M o r} \mathbf{2}^{\mathbf{n}} \mathbf{Q P S K}(\mathrm{n}$ : is serial to parallel ratiothrough $\mathbf{1} \mathbf{n}$ ratio). The future systems for JCDMA are accomplished, and how easy can be programing from severalfactor and features, the receiver will be at this point as the end user or for further general form as the down link scheme, or it is be able as with $\mathrm{PN}_{\mathrm{k}}=1$ for all $(\mathrm{k})$ or (users):

$\mathrm{d}_{\mathrm{h}}^{\mathrm{G}}=\sum_{\mathrm{k}=0}^{\mathrm{n}-1}\left\{\mathrm{~d}_{\mathrm{A}}^{\mathrm{G}} \operatorname{Code}_{\mathrm{h}}\right\}=\sum\left[\left[\sum_{\mathrm{k}=0}^{\mathrm{n}-1} \mathrm{U}_{\mathrm{k}} \mathrm{PN}_{\mathrm{k}}\left\{\mathrm{C}_{(\mathrm{k}+1, \mathrm{~m})}\right\}_{\mathrm{m}=1}^{\mathrm{L}}\right] *\left\{\mathrm{C}_{(\mathrm{h}, \mathrm{m})}\right\}_{\mathrm{m}=1}^{\mathrm{L}}\right]$

If we want the receiver and the Eq. 27 as Fig. 2 to work properly fordemodulation all signals for whichever user in Eq.27, it is be required tomeet the condition as in Eq. 28 below:

$\sum\left\{\mathrm{C}_{(\mathbf{k}+\mathbf{1}, \mathrm{m})}\right\}_{\mathrm{m}=1}^{\mathrm{L}} *\left\{\mathrm{C}_{(\mathbf{h}, \mathrm{m})}\right\}_{\mathrm{m}=1}^{\mathrm{L}}= \begin{cases}1 \text { or constant } & \text { if } \mathbf{k}+\mathbf{1}=\mathbf{h} \\ 0 & \text { if } \mathbf{k}+\mathbf{1} \neq \mathbf{h}\end{cases}$

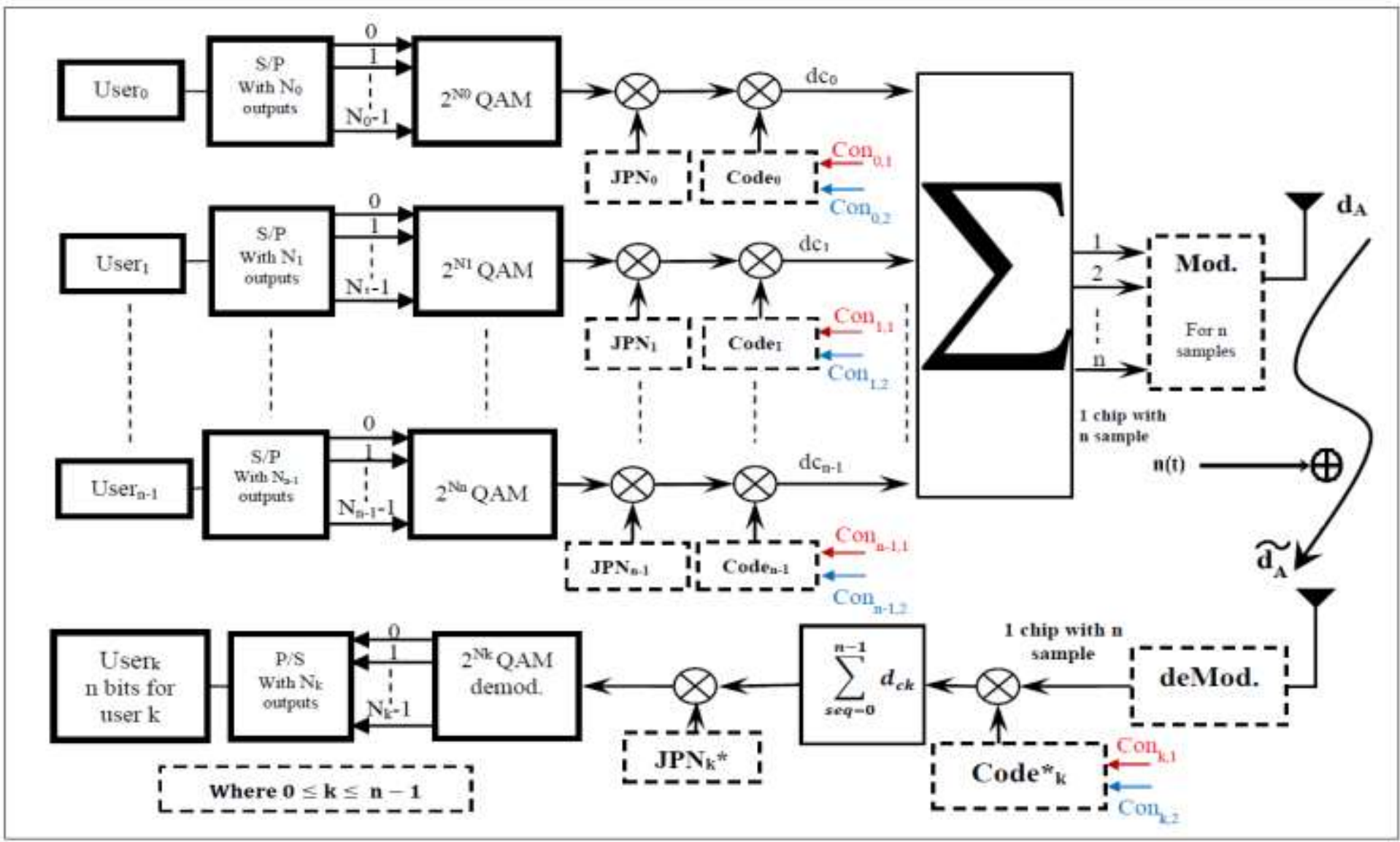

Figure2. The CDMA \& JCDMA with CH \& PSHWhere: $\widehat{\mathrm{d}_{\mathrm{A}}}=\mathrm{d}_{\mathrm{A}}+\mathrm{n}(\mathrm{t})$.(Mohammed, 2017). 
The Phase Hopping will be appliedby Eq.10 to Eq. 11 and the block diagram for the all system will see in Fig. 3 where Control for Phase Shifting and Code Hopping, and the Code Hopping will be used by Eq. 12 to Eq. 20 with deference orthogonal Codes similar to Wavelet group and Slentlet and so on , see references (Jassim et al., 2013), (Mohammed, 2012) exactly how to createa lot of orthogonal metrics and applied as Codes for requesting in DS-JCDMA. Table 1 Shows most variables that can be programmable, and that will compare with same old system and with both Phasing Shift and Code Hopping Speared Spectrum but in same settings below, in the Table 1. , it is clearlyas of the table, it can get our scheme with great security if all schemes Frequency Hopping Speared Spectrum (FHSS) and both with PSH, CH combined gather together.

\section{THE SUGGESTEDSCHEME FOR FHSS COMBINED WITH CH AND PSH}

TheFig. 3 and Table. 1 will introduce our novel scheme with its parameters and features, that willbe intended toFHSS with PSH and $\mathrm{CH}$ althoughmoreover with CDMA therefor we will rename as PSHSS, CHSS.

Fig. 3explains the total systemthat we previously proposed in this paper, all user data will be work as input for complex CDMA which is clearly described in (Mohammed, 2011), additionally in Fig. 2which is have PSH and $\mathrm{CH}$ controllers parametersalso we will use Eq. 25 for modulation and Eq. 27 for demodulation with, of certainly, Eq. 1 where $u(t)$ will be here DS-JCDMA data as shown below in Eq. 29 where both Fhss $(\mathrm{t})$ and $\mathrm{c}(\mathrm{t})$ find in Eq. 3 and Eq. 2respectively.

$\mathrm{d}_{\mathrm{A} 2}(\mathrm{t})=\left\{\sum_{\mathrm{k}=0}^{\mathrm{n}-1} \mathrm{Uq}_{\mathrm{K}}^{\mathrm{G}}\left\{\mathrm{C}_{(\mathrm{k}+1, \mathrm{~m})}\right\}_{\mathrm{m}=1}^{\mathrm{L}}\right\}_{1}^{\mathrm{G}} \cdot \mathrm{c}(\mathrm{t}) \cdot \operatorname{Fhss}(\mathrm{t})$

Table 1. Shows the variation of our parameters will work in this paper, While, Fig. 4 will explain the Fhss(t)functionsequence order time behavior which is will be random (Shin,H., et al., 2019)(Dvornikov, et al., 2019)for example in this paperwork $\{1,3,8,6,4,5,2,7\}$, and the 16QAM will use for all user and the packetsize will be 512.The test and resulting will transmitted over Additive White Gaussian Noise in wireless Channel (AWGN).Below is Table 1. which may find useful.

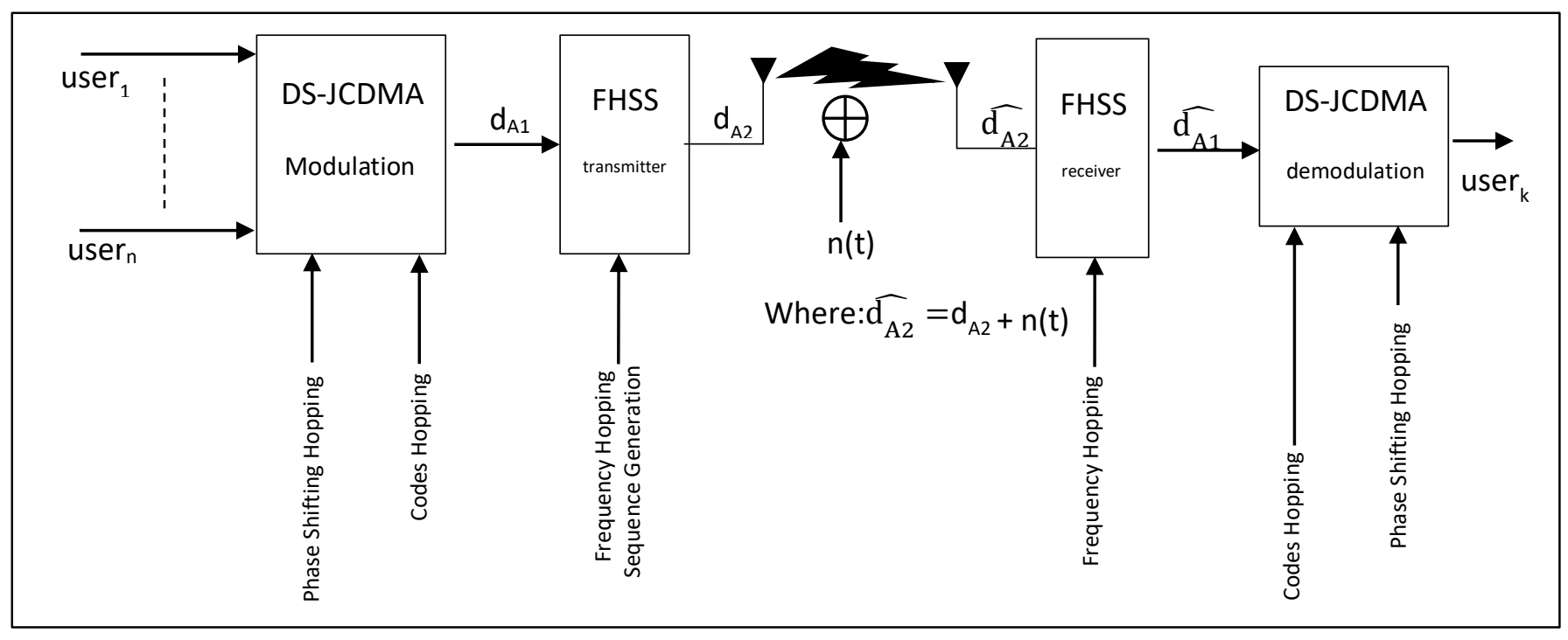

Figure3. The Block diagramof the new proposed system. 


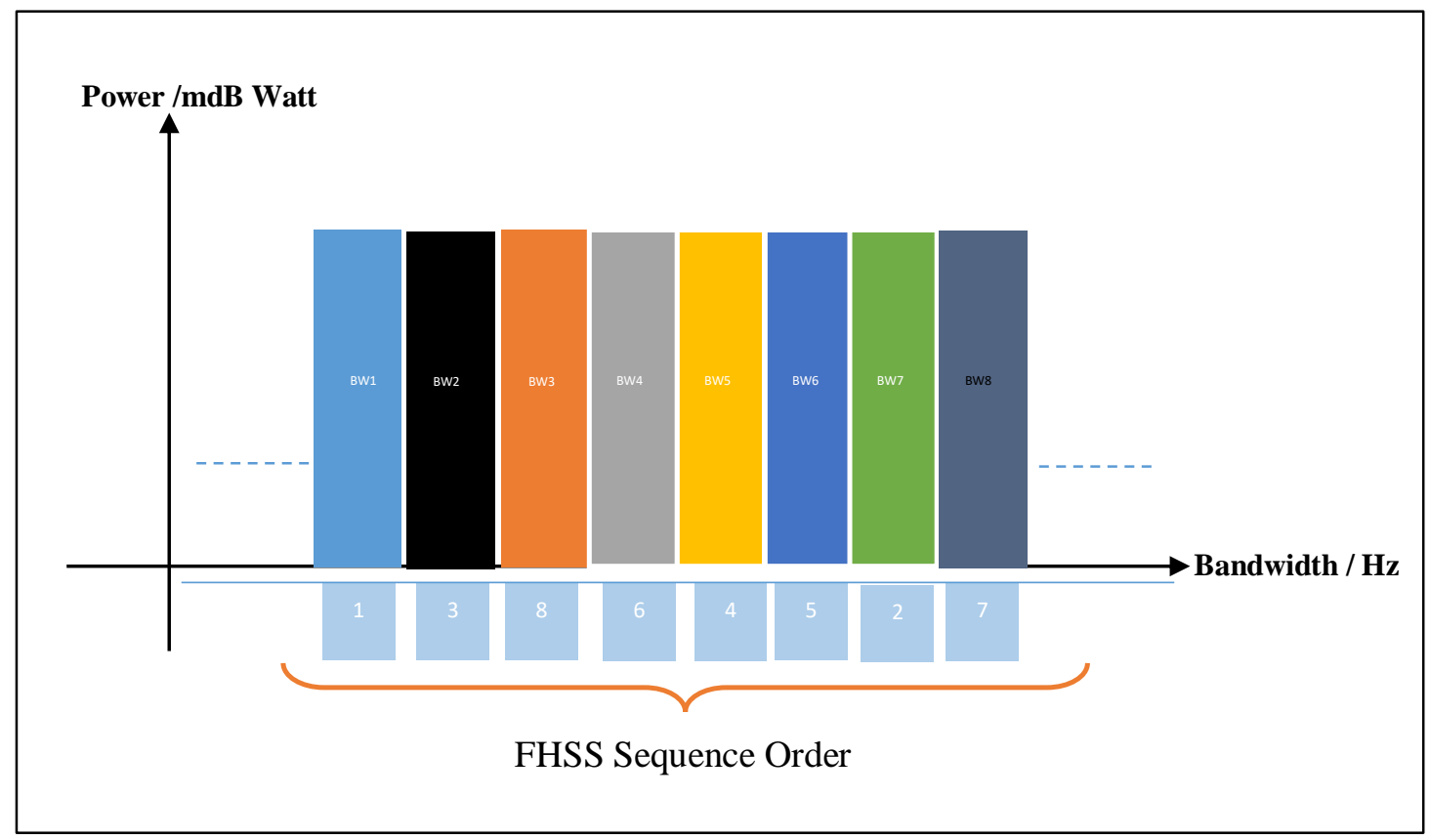

Figure4.SuggestRandomFHSS Sequence Hopping Time Order Proposed.

"Table 1. The parameters and its type, that desire be experiment in test "programming factors".

\begin{tabular}{|c|c|c|}
\hline \multicolumn{2}{|r|}{ Parameters } & Type \\
\hline 1 & Hopping Numbers per packet & 8 \\
\hline 2 & HoppingSequence & Randomly generation $=\{1,3,8,6,4,5,2,7\}$ \\
\hline 3 & Phase Hopping difference & $\Theta=0.1 \pi, 0.2 \pi, \ldots \pi$ and $-\Theta=0.1 \pi, 0.2 \pi, \ldots \ldots \ldots \pi$ \\
\hline 4 & Number of users & WCDMA $=8$ \\
\hline 5 & $\begin{array}{l}\text { Transform, for Code Hopping } \\
\text { Where here }(C) \text { for complex } \\
\text { number matrix and }(\mathrm{R}) \text { for real } \\
\text { number matrix for code hopping. }\end{array}$ & $\begin{array}{l}\text { 1- Walsh-Hadamard (W8), (R) } \\
\text { 2- Wavelet Transform matrix Dub28x8 (R) } \\
\text { 3- Slantlet transform matrix SLT8x8, (R) } \\
\text { 4- Safe matrix }\left({ }_{0} \mathbb{S}_{8}\right),(\mathrm{C}) \\
\text { 5-Complex-Wavelet filtermatrix (WSafe2) 8x8, (C) } \\
\text { 6- Fourier matrix FFT8x8, (C) }\end{array}$ \\
\hline 6 & Chips number for single packet & 8 \\
\hline 7 & Total Number of bits/packets & $8^{*}($ Number of bits/users/chip) No. of packet $=512$ each time \\
\hline 8 & Channel model & AWGN. \\
\hline 9 & Binary Modulation for all user & 16QAM \\
\hline 10 & AnalogModulation ways & FHSS \\
\hline
\end{tabular}




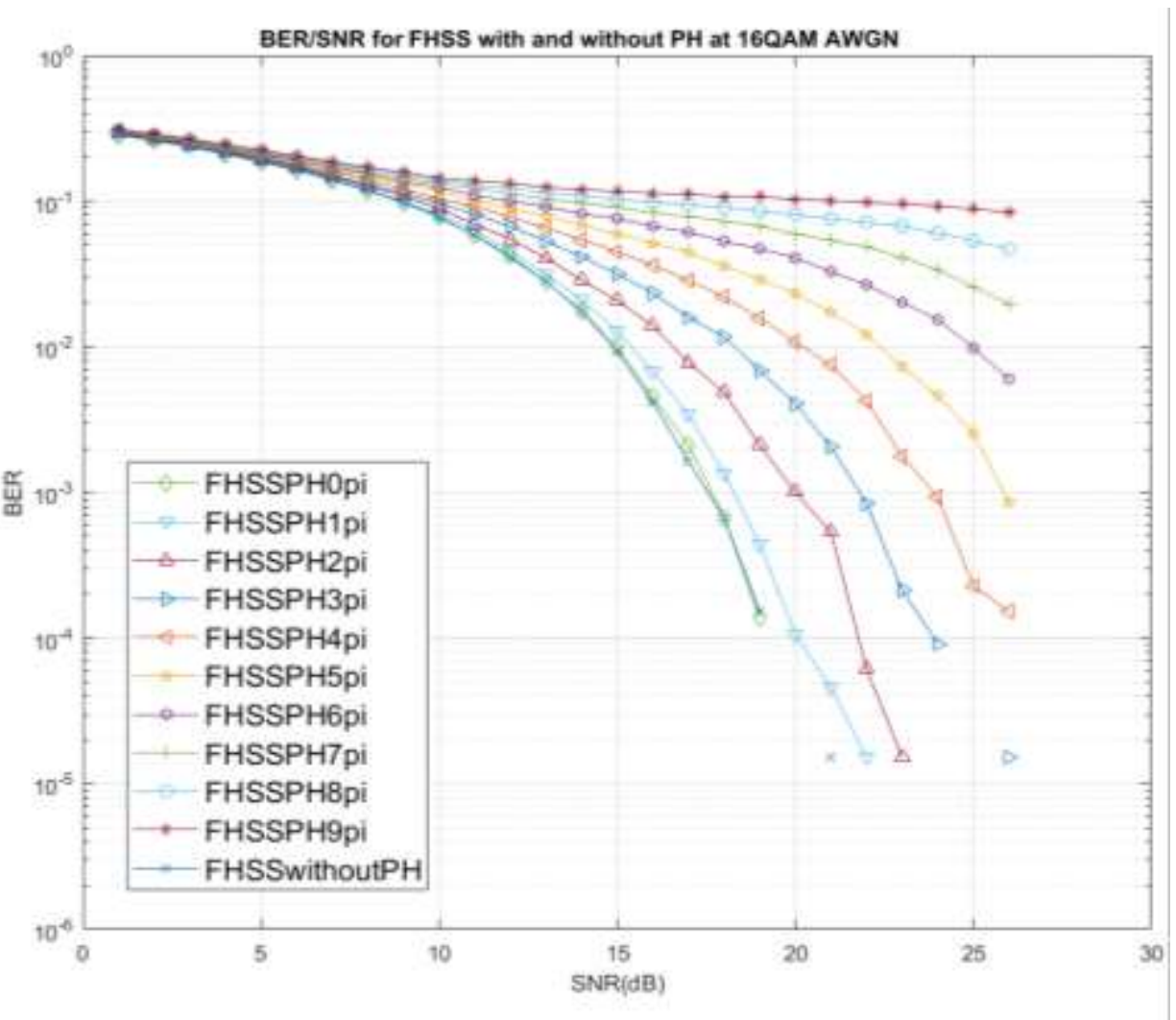

Figure6.BER/SNR Performance for FHSS with PSHSS in CDMA using Walsh Hadamard transform as Code with always zero phase different in receiver.

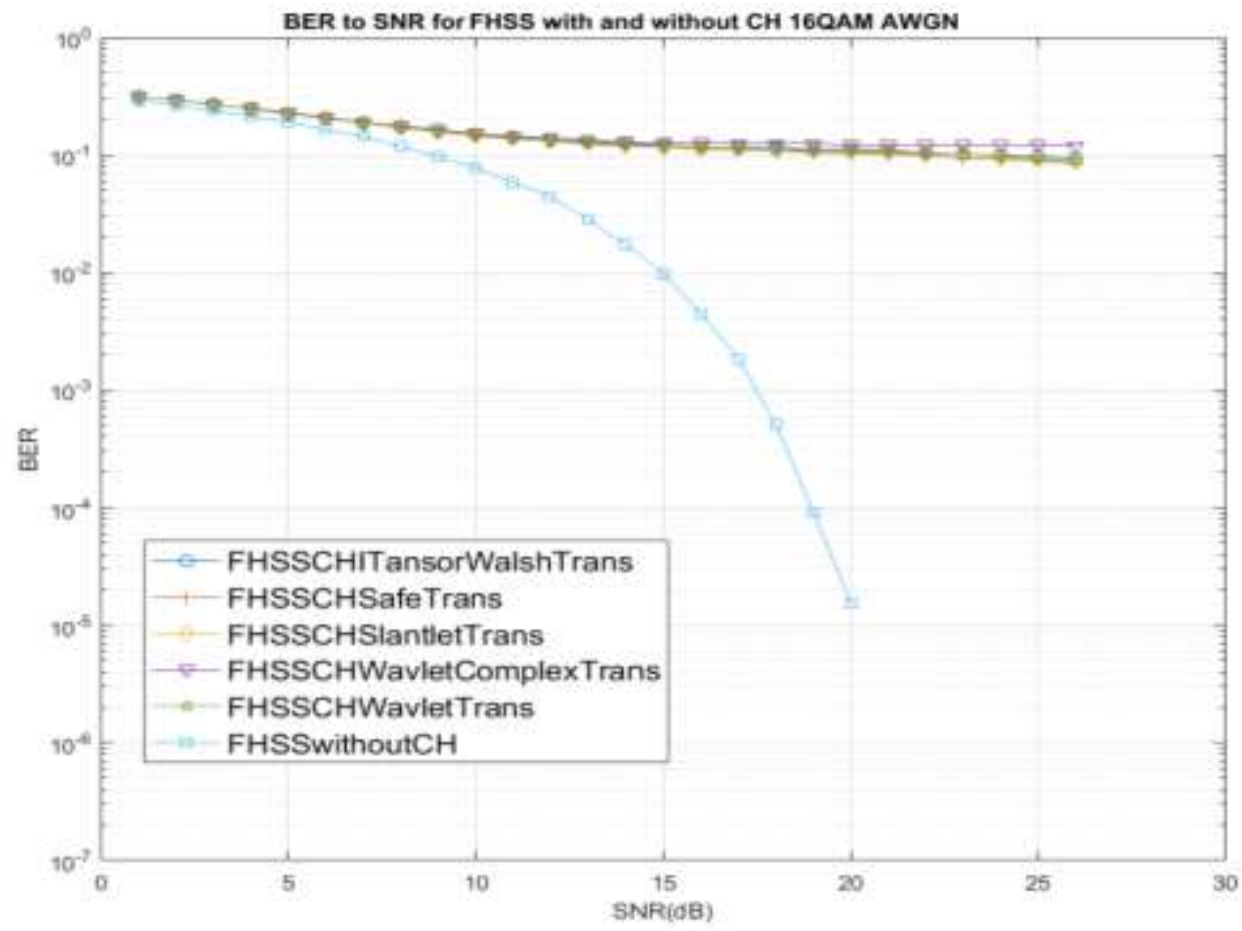

Figure7.BER/SNR Performance for FHSS with CHSS using Walsh Hadamard transform as Code with always zero phase different in transmitter and receiver transform code. 


\section{CONCLUSIONS AND DISCUSSION FOR FIGURES RESULTS}

All figures The foremost Result as shown will be exposed to the viewer that, it imaginable to make the new scheme that proposed FHSS and PH or CH, the results above compare between the Phase Hopping and Code hopping in DS-JCDMA with FHSS in Additive White Gaussian Noise (AWGN) wireless channel, therefore the results enlighten that the Code Hopping with FHSS (CHFHSS) is extra protected from the Phase Shift Hopping with FHSS (PSH-FHSS), and we can using together systems if its requirement extra protected scheme in the same time exclusive of growing physical layer.

SinceFig. 6to Fig.7, it can be considerate that in the primary CH-FHSS is equivalent FHSS without $\mathrm{CH}$, but it is furthermore protected and secure, when transmittingthe wireless data. Also reviewer noticeably, from Fig. 6, which from it can be seen that from the results above, the outcome of shifting in phase angle will be few in to transmitted and some outcome more effect and so on when the Phase Shifting are increase there for the result acceptable and accumulationsupplementarysafety for this ourscheme.

Similarly, from Fig.7it realized that the using $\mathrm{CH}$ by changing transforms code in the transmitterand in the receiver but with orthogonal code instead on Walsh Hadamard in CDMA at the transmitter and by defaulting similarly Walsh Hadamard in the receiver. For example, Wavelet Transform matrix,Slantlet transform matrix, Safe matrix, Complex-Wavelet Transform matrix (WSafe2) and Fourier matrix FFT.The system's parametersat the Table 1. is programmable for customize techniques as imperative and as we will use in the future.

From figuresabove that the results atFig. 6 and Fig. 7 for the proposal scheme, it been realizing that it can be increasing bit rate not includingexpanding bandwidth for everyone "users" or single user split up.

Conclusively, It can be gotten that since the results exceeding, the proposed scheme can be functionedwith orthogonal matrix as code with complex numbers elements and orthogonal matrix with real number elements, which is mostly likely one, and that actualsignificant and respectable for having extra security in $\mathrm{CH}$ for physical layer if using Theorem $\mathbf{2}$ and Theorem $\mathbf{2 . 1}$ from as presented in outcome for Fig.7. The signal receiver SNR towardsnumber of BER for the new scheme is acceptable at 16QAM (DS-JCDMA) on the AWGN wireless channel, therefor we are inspired to continue the research.

The new proposed system which is use in this paper pilot bits in addition using type channel estimator together with channel compensating, the result have beinginspiredus, and we sagest to use each above for WiFi or LTEA system integrated with JCDMA to improve security and BER to SNR. In the end as shown above, we have a system possible work like synthesized radio in both the code, the phase and frequency jointly without any complexity in one system, for many users with same bandwidth. 


\section{REFERNCES}

- Abdullah A. Jassim, Saifuldeen A. Mohammed, Ismael ShananDesher, November 2014. Bit Rate and Security Enhancement for DS-JCDMA Using IFFT and H-Polarity, V-Polarity Transmitter Waves. International Journal of Computer Applications (IJCA) Vol.95- No.3, pp.4-12.

- Abdullah Abdali Jassim, Saifuldeen A. Mohammed, Zainab Ibraheem, November 2013. Mixed Transforms Generated by Tensor Product and Applied in Data Processing. International Journal of Computer Applications (IJCA), Vol.81- No.19, pp.29-37.

- Alexander Pushnitski, Barry Simon, David Damanik, January 30, 2008. The Analytic Theory of Matrix Orthogonal Polynomials. John Wiley.

- B.Widiyatmoko, D.Bayuwati. E.Kurniawan, E. Yuniarti, F.G.A.K. Bawahab, November 2018, Performance evaluation and mathematical analysis of direct sequence and frequency hopping spread spectrum systems under wideband interference. International Journal of Advances in Intelligent Informatics ISSN 2442-6571 Vol. 4, No. 3, pp. 180-191

- D. A. Visan, L. Mihai Ionescu, A. G. Mazare and I. Lita, 2019, Transmission Module with Frequency Hopping for Wireless Sensor Mesh Networks Used in Plant Stress Monitoring Systems, IEEE 25th International Symposium for Design and Technology in Electronic Packaging (SIITME), pp. 86-89, Cluj-Napoca, Romania.

- D. Mototolea, R. Youssef, E. Radoi and I. Nicolaescu, 2020, Non-cooperative low-complexity detection approach for FHSS-GFSK drone control signals, in IEEE Open Journal of the Communications Society online. USA

- IEEE Standard for Wireless LAN Medium Access Control (MAC) and Physical Layer (PHY) specifications, 18 Nov. 1997, in IEEE Std 802.11-1997, pp.1-445, USA

- N.Chayat and BreezeCom, 1996, Frequency Hopping Spread SpectrumPHY of the 802.11 Wireless LANStandard, Presentation to IEEE 802March 11, 1996, IEEE USA.

- Jennifer Seberry, 1983. On Orthogonal Matrices with Constant Diagonal" Department of Applied Mathematics, University of Sydney, Sydney, Australia.

- K.G.Beauchamp, 1984. Application of Walsh and Related Functions with an Introduction to Sequence Theory. University of Lancaster, Lancaster, England, ACADEMIC PRESS.

- P. D. White, R. M. Buehrer and W. C. Headley, 2019, FHSS Signal Separation using Constrained Clustering,IEEE Military Communications Conference 2019 (MILCOM), pp. 159-164.Norfolk, VA, USA.

- S. V. Dvornikov, S. D. Erokhin and S. S. Dvornikov,2019, Frequency Selection for FHSS Mode, Systems of Signal Synchronization, Generating and Processing in Telecommunications (SYNCHROINFO), pp. 1-4, Russia.

- Saifuldeen A. Mohammed, SulaimanM.AbbasSlantlet 2006/9, Transform-Based Ofdm Scheme. Journal of Engineering, Volume 13 Issue 3 Pages pp. 1638-1647 Publisher Journal of Engineering. 
- Saifuldeen A. Mohammed, 2017, Phase Shift and Code Hopping Spread Spectrum Physical Layer Design and Implementation. International Journal of Soft Computing and Software Engineering [JSCSE] Volume 7 Issue 1 Pages 1-12 Publisher JSCSE.

- Saifuldeen A. Mohammed, April 2011, Proposed System to Increase the Bits rate for User in the Chip packet using Complex number in Code Division Multiplexing Access and Pseudo Noise (JCDMA and JPN)", Published in the proceeding of the Second Scientific Conference of Electrical Engineering University of Technology 4-5 CE13 pp 200-211. Iraq

- Saifuldeen A. Mohammed, 2012. A Propose for a Quadrature - Phase as Full Orthogonal Matrix Transform Compared with FFT Matrix Multiplication and Applied in OFDM System (Safe Transform the Fourier Twins), International Journal of Soft Computing and Software Engineering [JSCSE] Doi :10.7321/jscse. Vol. 2, No.6.5, Jun pp : 56-72.

- Saifuldeen Abdulameer Mohammed, June 2007, Space Time Block Code for PCC, MC-CDMA Using Slantlet Transform, M.Sc, Thesis, Electrical Engineering Department, College of Engineering, Baghdad University.

- Shin, H., Choi, K., Park, Y., Choi, J., \& Kim, Y. (2016). Security Analysis of FHSS-type Drone Controller. Lecture Notes in Computer Science, 240-253. doi:10.1007/978-3-319-31875-2_20.

- V. Vermeer, 1997, Wireless LANs; why IEEE 802.11 DSSS?, WESCON/97 Conference Proceedings, pp. 172-178, Santa Clara, CA, USA. 